\title{
ANALISIS KESEHATAN BANK DENGAN METODE CAMEL(STUDI KASUS : PT. BANK TABUNGAN NEGARA, TBK PERIODE 2011-2015)
}

\author{
Ratna Kurnia Sari \\ Program Studi Komputerisasi Akuntansi Universitas BSI Tegal \\ Email :ratna.rus@bsi.ac.id
}

\begin{abstract}
Lately the term healthy or unhealthy bank is increasingly popular. Actual events, about banks such as mergers and liquidation are always linked to the health of the bank. Therefore, a bank certainly needs an analysis to know its condition after doing operational activities, especially in a certain period of time. The analysis is done here in the form of bank soundness rating. The health of a bank is a bank's ability to conduct normal banking operations and be able to full fill all its obligations well in ways in accordance with prevailing banking regulations. While the goal to be achieved in this study is to determine the financial performance of PT. Bank Tabungan Negara, Tbk reviewed based on bank health analysis using CAMEL method, 2011-2015 period. Data analysis method used here refers to comparative descriptive analysis, where the financial statements will be analysis in terms of capital, assets, management, earnings and liquidity in order to obtain comparison of results in each year, so it will appear the level of finance and performance of the bank. While the data source used in this study is secondary data in the form of documents of banking financial statements from 2011 to 2015 obtained from the website of PT. Bank Tabungan Negara, Tbk is www.btn.co.id. The results obtained are CAR, NPL, BOPO, NIM, ROA, ROE and LDR, PT. Bank Tabungan Negara, Tbk declared less healthy. This is due to a decrease in management terms. In addition, in terms of profitability (ROA and ROE) also occurred a decline that causes banks to establish reserve impairment losses due to increased ratio of non-performing loans or bad loans.
\end{abstract}

Keywords: bank, bank health, CAMEL method

\section{PENDAHULUAN}

Perbankan merupakan salah satu faktor ekonomi yang sangat penting perannya dalam pembangunan ekonomi Indonesia terutama dalam menghadapi era pasar bebas dan globalisasi, baik sebagai perantara antara sektor defisit dan sektor surplus maupun sebagai agent of development, yang dalam hal ini masih dibebankan pada bank-bank pemerintah (Dedy, 2003 : 3).

Akhir-akhir ini istilah bank sehat atau tidak sehat semakin populer.Berbagai kejadian aktual, tentang perbankan seperti merger dan likuidasi selalu dikaitkan dengan kesehatan bank tersebut.Oleh karena itu, sebuah bank tentunya memerlukan suatu analisis untuk mengetahui kondisinya setelah melakukan kegiatan operasional, terutama dalam jangka waktu tertentu.Analisis yang dilakukan di sini berupa penilaian tingkat kesehatan bank.Kesehatan suatu bank adalah kemampuan bank untuk melakukan kegiatan operasional perbankan secara normal dan mampu memenuhi semua kewajibannya dengan baik dengan caracara yang sesuai dengan peraturan perbankan yang berlaku. 
Bank Indonesia selaku Bank Sentral mempunyai peranan yang penting dalam penyehatan perbankan. Hal ini disebabkan Bank Indonesia bertugas mengatur dan mengawasi jalannya kegiatan operasional bank. Untuk itu Bank Indonesia menetapkan suatu ketentuan yang harus dipenuhi dan dilaksanakan oleh lembaga perbankan, yaitu berdasarkan surat keputusan Direksi Bank Indonesia nomor 30/12/KEP/DIR dan Surat Edaran Bank Indonesia No. 30/3/UPPB tanggal 30 April 1997 yaitu tentang Tata Cara Penilaian Tingkat Kesehatan Bank Indonesia.

Dengan adanya analisa laporan keuangan dapat diketahui tingkat kinerja suatu bank.Karena tingkat kinerja merupakan salah satu alat pengontrol kelangsungan hidup. Dari laporan keuangan, maka akan diketahui tingkat kinerja suatu bank (sehat atau tidak sehat).

\section{METODE PENELITIAN}

\section{Jenis Penelitian}

Jenis penelitian yang digunakan berupa penelitian deskriptif komparatif, yaitu dengan meneliti laporan keuangan pertahun dengan mengunakan analisis CAMEL pada laporan keuangan lalu dibandingkan dengan laporan keuangan lainnya sehingga dapat diketahui tingkat
Dan untuk mengetahui sehat atau tidak sehatnya suatu perbankan, dapat dianalisis melalui aspek yang dilakukan oleh Bank Indonesia, yaitu menggunakan metode CAMEL (Capital, Asset, Management, Earning, dan Liquidity).CAMEL merupakan faktor yang sangat menentukan predikat kesehatan suatu bank.Aspek tersebut satu dengan yang lainnya saling berkaitan dan tidak dapat dipisahkan.Penilaian kesehatan bank meliputi 4 kriteria yaitu nilai kredit $81 \mathrm{~s} / \mathrm{d}$ 100 (sehat), nilai kredit 66 s/d 81 (cukup sehat), nilai kredit $51 \mathrm{~s} / \mathrm{d} 66$ (kurang sehat), dan nilai kredit $0 \mathrm{~s} / \mathrm{d} 51$ (tidak sehat).

Tujuan yang ingin dicapai dalam penelitian ini adalah untuk mengetahui kinerja keuangan PT. Bank Tabungan Negara, Tbk yang ditinjau berdasarkan analisis kesehatan bank menggunakan metode CAMEL.

kinerja keuangan pada PT. Bank Tabungan Negara, Tbk.

\section{Jenis dan Sumber Data}

Menurut Soeratno (2008:67), jenis data dapat dibedakan menjadi dua, yaitu :

1) Data kualitatif, merupakan data yang tidak dapat diukur dalam skala numerik atau data yang disajikan secara deskriptif atau yang berbentuk uraian. 
2) Data kuantitatif, merupakan data yang disajikan dalam bentuk skala numerik (angka-angka), namun dalam statistik semua data harus dalam bentuk angka, maka data kulitatif umumnya dikuatitatifkan agar dapat diproses.

Dalam penelitian ini jenis data yang digunakan adalah data kualitatif yaitu profil perusahaan dan data kuantitatif yaitu laporan keuangan tahun 2011-2015.

Sedangkan sumber data menurut Kuncoro (2008:127), dibedakan menjadi dua,yaitu :

1) Data primer
Sumber data penelitian yang diperoleh secara langsung dari sumber asli (tidak melalui media perantara).

2) Data Sekunder

Sumber data penelitian yang diperoleh secara tidak langsung memalui perantara (diperoleh dan dicatat oleh pihak lain).

Sumber data yang digunakan dalam penelitian ini adalah data sekunder yang berupa dokumen laporan keuangan perbankan dari tahun 2011 sampai 2015 yang diperoleh dari website PT. Bank Tabungan Negara, Tbk yaitu www.btn.co.id 


\section{HASIL DAN PEMBAHASAN}

\section{A. Hasil Penelitian}

Tabel 1. Hasil Analisis CAMEL PT. Bank Tabungan Negara, Tbk Periode 2011-2015

\begin{tabular}{|c|c|c|c|c|c|}
\hline \multirow{2}{*}{ PERHITUNGAN CAMEL } & \multicolumn{5}{|c|}{ TAHUN } \\
\cline { 2 - 6 } & $\mathbf{2 0 1 1}$ & $\mathbf{2 0 1 2}$ & $\mathbf{2 0 1 3}$ & $\mathbf{2 0 1 4}$ & $\mathbf{2 0 1 5}$ \\
\hline Capital (CAR) & $15,03 \%$ & $17,69 \%$ & $15,62 \%$ & $14,64 \%$ & $16,97 \%$ \\
\hline Assets (NPL) & $2,23 \%$ & $3,12 \%$ & $3,04 \%$ & $2,76 \%$ & $2,11 \%$ \\
\hline Management (BOPO) & $81,75 \%$ & $80,74 \%$ & $82,19 \%$ & $88,97 \%$ & $84,83 \%$ \\
\hline Management (NIM) & $5,76 \%$ & $5,83 \%$ & $5,44 \%$ & $4,47 \%$ & $4,87 \%$ \\
\hline Earning (ROA) & $2,03 \%$ & $1,94 \%$ & $1,79 \%$ & $1,14 \%$ & $1,61 \%$ \\
\hline Earning (ROE) & $17,65 \%$ & $18,23 \%$ & $16,05 \%$ & $10,95 \%$ & $16,84 \%$ \\
\hline Liquidity (LDR) & $102,57 \%$ & $100,90 \%$ & $54,69 \%$ & $63,68 \%$ & $78,74 \%$ \\
\hline
\end{tabular}

\section{B. Analisis Pembahasan}

\section{1) Permodalan (Capital)}

Berdasarkan tabel diatas, rasio CAR terendah terjadi pada tahun 2014 yaitu sebesar 14.64\%.Penurunan ini disebabkan adanya kinerja ekonomi Indonesia yang mengalami perlambatan dibandingkan dengan tahun sebelumnya. Mengacu pada surat edaran Bank Indonesia Nomor 6/23/DPNP tanggal 31 Mei 2004 bahwa nilai CAR di atas $8 \%$ dikatakan dalam kondisi sehat. Nilai CAR pada tabel di atas dapat dilihat bahwa secara keseluruhan berada di atas $8 \%$ meskipun terjadi perubahan di setiap tahunnya.Semakin tingginya nilai CAR, maka semakin baik kemampuan sebuah bank tersebut dalam menanggung kemungkinan resiko dari setiap kredit atau aktiva produktif yang beresiko.

\section{2) Kualitas Aset (Asset Quality)}

Dari tabel di atas, nilai NPL cenderung tinggi dari tahun ke tahun, terutama pada tahun 2011-2013.Penyebab tingginya nilai NPL tersebut adalah meningkatnya kredit macet oleh para nasabah terutama yang berpenghasilan minim.Seperti diketahui, Bank Tabungan Negara adalah perbankan yang berfokus pada pembiayaan kredit rumah.Dan dalam hal ini,PT. Bank Tabungan Negara, Tbk tergolong buruk dan ceroboh saat memberikan persetujuan kredit sehingga mengalami kesulitan dalam mengelola nilai NPL nya.NPL sendiri 
merupakan kredit bermasalah yang merupakan salah satu indikator kunci untuk dapat menilai kesehatan sebuah bank.Sedangkan kredit bermasalah adalah kondisi dimana nasabah tidak mampu lagi membayar kewajibannya kepada bank baik sebagian maupun seluruh kewajibannya dengan perjanjian yang telah disepakati.Sesuai edaran Bank Indonesia, nilai NPL dikatakan sehat apabila kurang dari $5 \%$.

\section{3) Manajemen (Management)}

Berdasarkan tabel di atas, PT. Bank Tabungan Negara, Tbk belum bisa mengendalikan biaya operasional perusahaannya dengan baik.Hal ini terlihat dari tingginya nilai BOPO dari tahun 20112015.Sebab menurut ketentuan Bank Indonesia, batas maksimum BOPO adalah 96\%.BOPO sendiri digunakan sebagai standar pengukuran aspek manajemen, di mana semakin rendahnya BOPO menunjukkan bahwa manajemen mampu mengendalikan biaya operasional yang dihadapi dalam rangka mempertahankan ataupun meningkatkan pendapatan operasionalnya.

Begitupula pada rasio NIM nya, PT. Bank Tabungan Negara, Tbk masih jauh dari acuan Peraturan Bank Indonesia di mana standart NIM yang ditetapkan adalah 3\%. NIM (Net Interest Margin) merupakan

salah satu patokan untuk mengetahui seberapa besar kemampuan bank dalam mengelola seluruh aktiva produktifnya supaya bisa menghasilkan penghasilan neto yang lebih tinggi. Karena semakin tinggi nilai NIM akan membuat bank dengan mudah menghindari resiko perbankan. Untuk itu, dengan pengelolaan manajemen yang baik maka kinerja operasional perusahaan pun berjalan dengan baik pula.

\section{4) Pendapatan (Earnings)}

Dari tabel di atas, profitabilitas PT. Bank Tabungan Negara, Tbk memiliki nilai yang buruk.Hal ini terlihat dari penurunan ROA dan ROE dari tahun ke tahun.Penurunan ROA ini disebabkan bank membentuk cadangan kerugian penurunan nilai yang mengakibatkan meningkatnya rasio kredit bermasalah atau kredit macet.Dengan meningkatnya NPL membuat bank harus berusaha mengurangi keuntungannya guna menghapus kredit macet tersebut.Tetapi apabila sebuah bank mempunyai ROA lebih besar dari $1 \%$, maka bank dapat dikatakan produktif dalam mengelola aktivitasnya dalam menghasilkan keuntungan.

\section{5) Likuiditas (Liquidity)}


Berdasarkan tabel di atas, PT. Bank Tabungan Negara, Tbk memiliki rasio LDR lebih dari $100 \%$. Hal ini terlihat dari besarnya nilai di tahun 2011 yaitu sebesar $102,57 \%$. Sedangkan menurut surat edaran Bank Indonesia No.6/23/DPNP/2004 perihal tata cara penilaian tingkat kesehatan bank umum dikatakan sehat bila

\section{SIMPULAN DAN SARAN}

\section{Simpulan}

Berdasarkan hasil penelitian dan analisis data yang telah dilakukan, maka dapat diambil kesimpulan bahwa dilihat dari nilai CAR, NPL, BOPO, NIM, ROA, ROE dan LDR, PT. Bank Tabungan Negara, Tbk dinyatakan kurang sehat. Dari segi manajemen, perusahaan berada dalam kategori yang tidak baik, sehingga mengalami penurunan disetiap tahunnya.Sedangkan dari sisi profitabilitas (ROA dan ROE) terjadi penurunan yang menyebabkan bank membentuk cadangan kerugian penurunan nilai yang diakibatkan meningkatnya rasio kredit bermasalah atau kredit macet. rasio LDR 94,75 \%. Itu artinya LDR PT. Bank Tabungan Negara, Tbk dalam kondisi yang kurang sehat dan tidak sehat. Rasio LDR lebih dari $100 \%$ sangat berbahaya karena sangat berpotensi untuk mengalami krisis likuiditas jika terjadi bank run yaitu nasabah dengan panik menarik seluruh tabungannya.

\section{Saran}

Dari hasil kesimpulan yang telah diuraikan di atas, maka saran yang dapat diberikan adalah :

1. PT. Bank Tabungan Negara, Tbk bisa melakukan kinerja keuangan menggunakan metode CAMEL secara periodik. Hal ini dimaksudkan supaya dapat meningkatkan kinerja keuangan di masa yang akan datang.

2. PT. Bank Tabungan Negara, Tbk mampu melakukan pengawasan yang lebih ketat khususnya dalam hal pemberian kredit. Hal ini dimaksudkan supaya dapat mengurangi tingkat kredit macet di masa yang akan datang. Karena keputusan pemberian kredit akan berpengaruh pada nilai NPL dan ROA. 


\section{DAFTAR PUSTAKA}

Bank Indonesia, SK DIR BI Nomor 30/21/KEP/DIR tanggal 30 April 1997.perihal Tatacara Penilaian Kesehatan Bank Umum.

Bank Indonesia, PBI No. 6/10/PBI/2004 Tanggal 12 April Tentang Sistem PenilaianTingkat Kesehatan Bank Umum.

Darmawi Herman 2014, Manajemen Perbankan, PT. Bumi Aksara, Jakarta.

Dedy Handoko, 2003, Metode CAMEL Untuk Mengevaluasi Kinerja Bank Hasil Merger (Studi Kasus Pada Bank Mandiri dan Bank Central Asia), Jurnal Ekonomi Pasca Sarjana Universitas Brawijaya, Hal 1-19, Malang.

Dendawijaya, Lukman 2008, Manajemen Perbankan, cetakan ketiga, Penerbit : Ghalia Indonesia, Jakarta

Kasmir, 2008, Analisis Laporan Keuangan, edisi pertama, cetakan pertama, Penerbit : Rajawali Pers, Jakarta
Kuncoro, Mudrajad. 2008. Metode Riset Untuk Bisnis dan Ekonomi. Erlangga, Jakarta.

Laporan Keuangan PT. Bank Tabungan Negara, Tbk.

Meirisa Faradila (2017), Analisa Tingkat Kesehatan Perbankan Metode Camels (Studi Kasus Pada Bank Milik Pemerintah Yang Terdaftar Di Bursa Efek Indonesia Periode 20112015), Jurnal Ilmiah STIE MDP, Hal 131-140

Munawir, 2010.Analisis Laporan Keuangan. Liberty. Yogyakarta.

Nuritomo, Totok Budisantoso 2014, Bank dan Lembaga Keuangan Lain, Salemba Empat, Jakarta.

Ruddy Tri Santoso, Drs, 1997, Mengenal Dunia Perbankan, ANDI, Yogyakarta.

Soeratno.2008. Metode Penelitian Untuk Ekonomi dan Bisnis. Andi, Yogyakarta.

Sri Pujiyanti (2009), Analisis Kinerja Keuangan Mengenai Tingkat Kesehatan Bank Dengan 
Menggunakan Metode CAMEL

(Studi Kasus Pada PT. Bank Negara

Indonesia (Persero) Tbk Dan PT.

Bank Bukopin Tbk Periode 2006-

2008) 